\title{
HumanOS E NÃO-HUMANOS NO UNIVERSO TRANSFORMACIONAL DOS RIBEIRINHOS DO RIO TAPAJÓS -PARÁ ${ }^{l}$
}

\author{
João Valentin Wawzyniak ${ }^{2}$
}

\begin{abstract}
Resumo
A partir de dados etnográficos resultantes da pesquisa de campo realizada, entre 2005 e 2007, em comunidades situadas às margens do baixo rio Tapajós, Pará, esta comunicação abordará a dimensão social da relação entre humanos e não-humanos presente na cosmologia e no cotidiano dos ribeirinhos nelas residentes. Os princípios orientadores dessa relação são fornecidos pelo sistema cultural que postula a não existência de dicotomia ou antagonismo entre as dimensões natural, cultural e sobrenatural, mas, em seu lugar, postula um universo transformacional e povoado por uma pluralidade de agentes, humanos e não humanos. Tais seres, com poder de encantamento e agenciamento, transformam-se, em certas circunstâncias, uns nos outros. Transfiguram suas aparências e comportamentos, regulam e afetam o corpo e a vida cotidiana individual e coletiva. Nesse contexto etnográfico, algumas qualidades de seres — animais, humanos, objetos, espíritos e instituições — são apreendidascomo pessoas com quem podem estabelecer relações sociais, particularmente "acordos".
\end{abstract}

Palavras-chave: Ribeirinhos. Cosmologia. Amazônia.

\footnotetext{
${ }^{1}$ Trabalho apresentado na $27^{\text {a }}$ Reunião Brasileira de Antropologia, realizada entre os dias 01 e 04 de agosto de 2010, Belém, Pará, Brasil. Revisado por Edilene Coffaci de Lima, em maio de 2012.

${ }^{2}$ Foi professor do Departamento de Ciências Sociais da Universidade Estadual de Londrina, Brasil, de 2001 até seu falecimento em agosto de 2011.
} 


\title{
HUMANS AND NON-HUMANS IN THE TRANSFORMATIONAL UNIVERSE OF RIPARIANS ON RIO TAPAJÓS - PARÁ
}

\begin{abstract}
The present study approaches the social dimension of the relationship between humans and non-humans in the cosmology and everyday lives of riparians, from etnographic data resulting from field research carried out between 2005 and 2007, within communities located on the banks of low Rio Tapajós, Pará. The guiding principles of this relationship are given by the cultural system, which postulates the non-existence of a dichotomy or antagonism between the natural, cultural and supernatural dimensions but, instead, postulates beings in a transformational universe populated by a plurality of agents, human and non-human. Such beings, with a power of enchantment and agency, transform into each other, under certain circumstances. They transfigure their appearances and behaviors, regulate and affect the body and individual and collective everyday life. In this ethnographic context, some qualities of beings - animals, humans, objects, spirits and institutions - are apprehended as people with whom they can establish social relationships, especially "deals".
\end{abstract}

Keywords: Riparians. Cosmology. The Amazon.

$\mathrm{C}$ ompreender o universo cultural das sociedades caboclas da Amazônia, mais especificamente dos ribeirinhos da região do interflúvio Tapajós/Arapiuns/ Amazonas, cuja cosmologia postula o reconhecimento da existência de seres com o poder de transformar sua aparência e com os quais se estabelecem relações sociais, é o objetivo mais amplo no qual este trabalho se insere. Tais seres afetam as condições de reprodução da natureza, dos indivíduos e da sociedade, por interferirem na vida cotidiana, principalmente no que diz respeito à saúde humana e às relações dos humanos entre si, destes com os não humanos e com o meio ambiente. Busco responder a seguinte questão: quais constrangimentos sociais estão associados às relações entre os humanos e os diferentes seres?

Na bibliografia antropológica sobre a cultura do caboclo amazônico são recorrentes as referências aos seres que se metamorfoseiam em outros, inclusive em humanos, capazes de causar distúrbios físicos e psicológicos nas pessoas, além de interferir nas atividades cotidianas (CRAVALHO, 1993, 1998; GALVÃO, 1976; HARRIS, 2000; LOUREIRO, 1995; LUNA, 2002; MAUÉS, 1997; NUNGENT, 1993; SILVA, 1980; SLATER, 2001; SMITH, 1996; WAGLEY, 1988), embora nem todos os 
autores definam esse fenômeno como objeto de análise ou o submetam a uma análise teórica mais específica.

A partir de dados etnográficos resultantes de pesquisa de campo realizada, entre 2005 e 2007 (WAWZYNIAK, 2008), em comunidades situadas às margens do baixo rio Tapajós ${ }^{3}$, Pará, esta comunicação abordará a dimensão social da relação entre humanos e não-humanos presente na cosmologia e no cotidiano dos ribeirinhos nelas residentes. Os princípios orientadores dessa relação são fornecidos pelo sistema cultural que postula a não existência de dicotomia ou antagonismo entre as dimensões natural, cultural e sobrenatural, mas, em seu lugar, postula um universo transformacional e povoado por uma pluralidade de agentes, humanos e não humanos. Acreditam os ribeirinhos que existem seres com poder de encantamento e agenciamento, os quais se transformam, em certas circunstâncias, uns nos outros. Transfiguram suas aparências e comportamentos, regulam e afetam o corpo e a vida cotidiana individual e coletiva. Nesse contexto etnográfico, algumas qualidades de seres - animais, humanos, objetos, espíritos instituições - são apreendidas como pessoas com quem se pode estabelecer relações sociais, particularmente "acordos".

Para situar a relação entre humanos e não humanos no interior da cosmologia e na vida cotidiana dos ribeirinhos do baixo Tapajós é preciso relacioná-la a outras dimensões, especialmente ao modo como eles concebem o ambiente da floresta e do rio. Nestes espaços, a presença dos "bichos" - seres que se metamorfoseiam em outros - é sentida, quando da sua manifestação, sob diferentes sinais e aparências.

A floresta é um espaço constituído de muitos lugares e dotado de múltiplos significados, "morada" de muitas e diferentes potências que afetam as condições de reprodução da natureza, dos indivíduos e da sociedade, pois interferem nas práticas cotidianas concernentes à saúde dos humanos, à relação destes entre si e com o meio ambiente. Para Da Matta (1993), existem seres e zonas intermediárias ligando a natureza com a cultura e sustentando o encantamento de ambos os domínios. De acordo com tal concepção, os diferentes espaços são apreendidos como domínio dos encantados, ou "bichos", que mediam a relação do homem com o meio, interferindo, então, nessa relação. São seus "donos", seres dotados de

\footnotetext{
${ }^{3}$ Aqui está sendo considerado baixo Tapajós a micro-região situada entre a extremidade sul da Floresta Nacional do Tapajós (Flona do Tapajós) e a foz do rio Tapajós, em frente à cidade de Santarém, onde ele se encontra com o rio Amazonas.
} 
poderes para regular o "movimento" da mata e do rio, bem como para prescrever, mediante "regulamentos", orientações sobre 0 uso dos recursos naturais neles existentes.

Os "donos" são seres espiritualizados, tratados como pessoas, "entidades morais", com quem os homens podem estabelecer relações sociais (DESCOLA, 1992; DA MATTA, 1993; FAUSTO, 2008; VIVEIROS DE CASTRO, 1996). Possuem a potencialidade virtual de transformarem suas aparências assumindo a "formatura" de outras espécies de seres, bem como definir, mediante "regulamentos", orientações para condutas adequadas de sociabilidade dos humanos entre si e destes com os não humanos. Outro aspecto importante da sua "ação eficaz sobre o mundo" (FAUSTO, 2008, p. 330) revela-se na capacidade de provocarem o adoecimento do indivíduo que transgride ou intenciona transgredir os seus "regulamentos". Entretanto, se em determinadas circunstâncias os "donos" provocam doenças, em outras são "invocados" pelos pajés ou curadores para auxiliarem no diagnóstico da doença e na indicação de procedimentos terapêuticos para curá-la.

Para Fausto (2008, p. 329), embora se valendo de exemplos etnográficos relativos às cosmologias indígenas, mas também aceitável para o contexto tapajônico, a categoria "dono" transcende a relação de domínio e propriedade, por consistir num "modo generalizado de relação assimétrica constituinte da sociabilidade amazônica". Trata-se, segundo o autor, de "um esquema relacional que define relações nas mais diferentes esferas", ao fornecer um modelo de pensamento e ação em diferentes circunstâncias e relações nas que a categoria está envolvida (FAUSTO, 2008, p. 348). Assim, também entre os ribeirinhos, dependendo da situação, o outro pode ser apreendido como uma possível manifestação, "engeramento", dos "donos" e suas "paragens"5 sob outras aparências.

\footnotetext{
${ }^{4}$ Para os ribeirinhos, todo conjunto de regras ordenadoras de relações são designadas de "regulamento". 0 termo está associado às normas impostas pelos seringalistas, "patrões", que ordenavam a utilização de práticas apropriadas para extração do látex, definiam regras que disciplinavam o trabalho e o convívio social nos seringais. De acordo com Teixeira, (1980, p. 89), "o regulamento tratava de reforçar a consciência do indivíduo no sentido de ser criada uma atitude favorável à natureza daquele trabalho". No Tapajós, os regulamentos podem não ter sido formalizados como em alguns seringais da Amazônia, mas isto não significa que a sua aplicação não fosse exigida e fiscalizada.

50 termo "paragem" refere-se a espaços sobre os quais os "bichos" exercem domínio, no sentido indicado por Fausto (2008).
} 
Segundo Da Matta (1973, p. 73), "o caçador e o pescador não encaram sua atividade como possuindo um caráter exclusivamente técnico; nela existem também elementos de ordem sobrenatural que parecem indicar a entrada do homem num universo governado por regras diferentes das que regem a sociedade humana"6. Entretanto, se considerarmos as análises de autores como Descola (1992, 1997), Arhem (1993, 1996), Viveiros de Castro (1996) e Rival (1998), essa diferença de regras pode ser menor do que sugere Da Matta (1973), uma vez que não se tratam de realidades distintas, mas contíguas.

Para ilustrar a atualidade e a generalidade do pensamento que postula a existência dos encantados entre os ribeirinhos, entre muitos exemplos possíveis, um é extremamente significativo por revelar a interface com outro sistema, o tecnológico. Trata-se de um episódio que demonstra a continuidade das concepções sobre a existência de seres encantados mesmo quando mediadas pelo sistema tecnológico de comunicação. Ele me foi relatado por um cinegrafista vinculado a uma organização não-governamental que atua na região.

Segundo esse entrevistado, há algum tempo atrás, quando gravou um vídeo sobre pesca predatória, aconteceu algo que o deixou surpreso. As personagens eram representadas por jovens da comunidade onde a gravação estava sendo realizada, e, numa determinada cena, o Boto saía da água para reclamar da utilização de bombas ${ }^{7}$ pelos pescadores, que as usam para matar peixes. No roteiro, estava definido que 0 ator que representava o Boto tiraria a cabeça para fora da água e assobiaria, imitando o "bicho". Esse ator perguntou, então, ao cinegrafista, qual a hora em que o vídeo passaria na televisão, e este lhe disse que seria à noite. Diante da resposta, aquele se recusou a fazer a imitação, alegando que não se imita 0 "bicho" durante a noite, mesmo através de imagem gravada em outro horário; se fizesse isso, o Boto viria "pegá-lo" - e a cena foi gravada sem o áudio do assobio.

Esse acontecimento indica a forte presença das concepções locais no cotidiano da população ribeirinha, as quais orientam também a sua relação com

\footnotetext{
${ }^{6}$ Ao contrário do que sugerem certas concepções que a sociedade ocidental faz dela mesma, que foram inclusive expressas por Da Matta não há oposição entre técnica e crenças sobrenaturais. Mais ainda, se lembrarmos que uma ética protestante parece estar no âmago da construção do capitalismo, a dissociação entre crença e técnica não seria válida nem mesmo para a sociedade ocidental.

${ }^{7}$ Bombas são petardos confeccionados com pólvora enrolada em panos e plástico que, atirados na água, explodem. É uma técnica usada por alguns e tem alto impacto sobre a fauna e a flora aquáticas.
} 
oùtros sistemās. Tal relação entre diferentes sistemas está presente inclusive nas esferas da saúde, da economia e da política, pois o caboclo ribeirinho apreende os eventos e exerce suas atividades cotidianas orientando-se por sua concepção do universo sociocósmico tapajônico.

Considero aceitável estender para a população ribeirinha do baixo Tapajós a afirmação de Rivière (1995, p. 192) para as sociedades indígenas: na Amazônia, 0 mundo é percebido como sendo "altamente transformacional, onde as aparências enganam”. E, como sugere Da Matta (1993), nesse universo transformacional não há limites claros nem fronteiras irredutíveis entre natureza e sociedade ou entre humanidade e não-humanidade. Para analisar a relação entre humanos e nãohumanos, adoto a noção de perspectivismo, pensamento característico de alguns sistemas cosmológicos indígenas, porque ele está centrado na corporalidade e concebe o mundo como sendo "habitado por diferentes espécies de sujeitos ou pessoas, humanas ou não-humanas, que o apreendem segundo pontos de vista distintos" (VIVEIROS DE CASTR0, 2002, p. 347); além disso, reconhece a condição humana a qualquer espécie que seja pensada como sujeito, isto é, seres dotados de intencionalidade. Além desses aspectos, segundo Viveiros de Castro (2002, p. 390), "não há mudança espiritual que não passe por uma transformação do corpo, por uma redefinição de suas afecções e capacidades". Cabe, contudo, lembrar o alerta de Erikson (2000, p. 44): não fazer do perspectivismo "uma interpretação por demais literal", e sim uma "dimensão metafórica da metamorfose".

As concepções desses ribeirinhos sobre corpo e pessoa parecem englobadas por um sistema cosmológico mais amplo sobre natureza e não-natureza, razão pela qual uso a noção de cosmologia proposta por Arhem (1996), que a define como um construto cultural holístico composto por um conjunto de representações e saberes que orienta os indivíduos, moral e existencialmente, na sua interação com a natureza. No contexto amazônico, trata-se de um sistema de pensamento em que os seres não-humanos possuem as mesmas faculdades, os mesmos comportamentos e códigos morais atribuídos aos seres humanos (DESCOLA, 1992, 1997), e, junto com estes, formam uma comunidade de pessoas ordenadas conforme os mesmos princípios (ARHEM, 1993; DESCOLA, 1992; GALVÃO, 1976; HARRIS, 2000; VIVEIROS DE CASTR0, 1996, 2002). Ou, nos termos de Latour (2001, p. 222), um coletivo no interior do qual ocorre um "intercâmbio de propriedades humanas e não humanas". Entre os ribeirinhos tapajônicos esse "intercâmbio" é expresso pelo termo "engerar". 


\section{"Engerar"}

A categoria nativa "engerar", recorrentemente usadas pelos ribeirinhos, indica o caráter transformacional dos seres do universo sociocósmico do Tapajós e revela-se instrumento de apreensão do mundo e de organização da experiência social.

Os ribeirinhos acreditam que os "bichos", seres capazes de mudar de aparência tanto física quanto comportamentalmente, sejam os agentes causadores de algumas modalidades de doenças e de interferir na vida cotidiana individual ou coletiva. A despeito de aparecerem fisicamente aos humanos ou de ser possível conversar com eles em algumas ocasiões, frequentemente eles permanecem invisíveis, sinalizando sua presença através de sons, "assobios", "pitiú" (odores característicos de cada ser ou de determinados estados) ou "misura".

Também os humanos podem transformar-se em outros seres. Explicam que os índios, quando muito velhos, embrenham-se na mata e, no isolamento, transformam-se em alguma espécie de "bicho". No caso, no Jurupari ou no Mapinguari, seres resultantes dessa metamorfose de humanos em nãohumanos, com poder de interferir na vida cotidiana das pessoas, afetando a sua consciência, levando-as a perder a memória e a desorientar-se na floresta ou no seu relacionamento social, ao romperem com normas e valores socialmente estabelecidos.

Recorrentemente, os ribeirinhos comentavam que algumas espécies de animais aquáticos assumem a forma humana para aparecer aos pescadores com o objetivo de conduzi-los aos "encantes" localizados no fundo do rio. E alguns relatos indicam que também objetos inanimados se transformam em seres animados, como pode ser constatado num episódio relatado pelo morador de uma das comunidades. Segundo esse ribeirinho uma flecha a ele presenteada por uma cunhada, numa noite, teria se transformado em cobra e tentado matá-lo.

Para exemplificar mais detalhadamente 0 poder de transformação dos seres, eu poderia lançar mão de vários deles existentes no universo dos comunitários ribeirinhos do baixo Tapajós: Boto, Jurupari, Mapinguari, Boiúna (Cobra Grande), Patauí, Matinta Pereira, Cunauarú. Entretanto, a Curupira, ser que "administra a mata", é o demiurgo que manifesta mais frequentemente sua

\footnotetext{
${ }^{8} 0$ termo "misura" indica a capacidade do "bicho" de manter-se invisível mas manifestar sua presença sob diferentes "formas" à pessoa da qual ele se aproxima.
} 
faculdade de metamorfosear-se em humanos, animais, objetos inanimados e mesmo em instituições públicas. Este "bicho" pode aparecer tanto com o corpo de um homem quanto com o de uma mulher. Seu comportamento, nesses casos, depende da circunstância e da forma sob a qual aparece ${ }^{9}$ — condição revelada nas formas de tratamento ("comadre", "compadre", "vovó", "vovô", "titia", "titio"), as quais indicam a possibilidade de também estabelecerem com eles relações de parentesco. Além disso, é o encantado a quem foi atribuída a maioria dos casos da "doença" denominada "mau-olhado de bicho" sobre a qual abordarei mais adiante.

Curupira tem sido recorrentemente descrita como um ser humano coberto de pelos ou como um menino cujos pés são voltados para trás, para desorientar os caçadores. Entretanto, essas são apenas duas entre as muitas formas sob as quais ela aparece. Curupira é um demiurgo pan-amazônico (ERIKSON, 2000), e sua primeira referência escrita data de 1560, feita por Anchieta. Este, descrevendo-a, assinala que ela revela notável plasticidade, pois incorpora diferentes atributos e formas físicas (KOK, 2001). Galvão (1976) informa que qualquer animal que apresente um comportamento estranho pode ser tomado, pelo caboclo ribeirinho, como sendo a Curupira.

Para os ribeirinhos, Curupira é uma "qualidade de bicho" dotado não só da capacidade de "engerar-se" na "formatura de gente", mas também de "engerarse" na "estatura de animal" que fala como um humano — ambiguidade manifesta sob diferentes aparências, diante das quais é preciso adotar atitude prudente, especialmente quando se anda pela floresta. Como conhece as intenções de um caçador, pode "engerar-se na formatura" de um animal para distraí-lo, enganá-lo e conduzi-lo para longe dos animais "da natureza". Isto é, animais não espiritualizados.

Como a categoria "bicho" pode, semanticamente, ser aplicada para classificar qualquer ser estranho ou potencialmente perigoso, ela abrange, além dos encantados, as agências modernizadoras e seus técnicos, os quais, sob diferentes "formaturas", aparecem repentinamente na vida cotidiana, individual ou coletiva,

${ }_{9}^{9}$ Alencar (2002), em seu estudo entre moradores da Reserva de Desenvolvimento Sustentável Mamirauá, no estado do Amazonas, escreve que Curupira pode assumir a forma da mãe de uma criança que pretenda levar consigo para ser seu esposo. A autora relata o caso de um homem que, após ser encantado pela Curupira, casou-se e viveu com ela durante vários anos, e somente após a intervenção de um curador da região foi desencantado e retirado do seu "domínio". 
tentando estabelecer novas "modas" (projetos), muitas delas conflitantes entre si e, sobretudo, com a tradicional.

Os ribeirinhos residentes nas comunidades situadas no perímetro da Floresta Nacional do Tapajós ${ }^{10}$ apreendem o Instituto Brasileiro do Meio Ambiente e dos Recursos Naturais Renováveis - IBAMA - como uma das formas assumidas pela Curupira (WAWZYNIAK, 2004). Tal associação decorre de uma série de analogias que fazem entre as atitudes e as ações das duas entidades. Em diferentes oportunidades, especialmente em reuniões, ouvi-os dizerem que o Ibama assemelha-se à Curupira porque o "pessoal do Ibama" numa hora aparece de um jeito e, em outra, de forma diferente. Essa apreensão leva-os a adotar uma atitude de respeito e, ao mesmo tempo, de suspeição em relação a esse órgão e aos seus funcionários, pois, ao longo dos anos, tem havido muitas mudanças nos seus discursos e nas suas ações — tal como faz a Curupira.

Entretanto, sempre procuraram manter abertas as condições de interlocução e seguir, ainda que não integralmente, os "regulamentos do governo". Como o "bicho", essa instituição pública federal tanto pode punir quem transgride as "leis" quanto estabelecer acordos, pessoais e institucionais, com os moradores ou as comunidades. Os acordos pessoais referiam-se aos "acertos" com os fiscais do Ibama por ocasião de alguma autuação - nesse caso, a pessoa autuada "presenteava" o fiscal para atenuar a pena ou liberar o "produto". Já os "contratos" institucionais - Termo de Ajustamento de Conduta denominado Plano de Manejo - davam-se entre esse órgão e as associações, numa negociação entre o que deveria ou não ser permitido em relação à caça, pesca e extração de produtos florestais.

A apreensão dos seres como possuidores de capacidade de transformar seu corpo mudando de aparência revela uma permanente construção e desconstrução da pessoa, que é levada a adotar diferentes atributos e a incorporar outros pontos de vista sobre si mesma e sobre os outros seres, humanos ou não-humanos. Contudo, cabe observar que mais importante que a intensidade do desfiguramento físico é 0 progressivo processo de transformação da pessoa.

Seguindo a orientação de Dumont (1993, p. 201), estabeleci as relações da categoria "engerar" com outros elementos da configuração global da cosmologia dos ribeirinhos e ver em que medida aquela oferece "ao pensamento os recursos de organização e operação do mundo", sobretudo os relacionados à saúde, ao

${ }^{10}$ Unidade federal de conservação criada em 1974 sem o conhecimento dos moradores.

HuMANOS E NÃO-HUMANOS NO UNIVERSO TRANSFORMACIONAL... 
corpo e à pessoa. 0 "engeramento" indica que não existem fronteiras rigorosas entre humanidade e animalidade, natureza e cultura (INGOLD, 1995; VIVEIROS DE CASTR0, 1996), pois para os ribeirinhos entre essas dimensões há uma formidável porosidade. A categoria "engerar" que denota essas transformações, na concepção dos ribeirinhos, está diretamente associada ao "mau-olhado de bicho" ou "assombro de olhada de bicho". Os "bichos" com capacidade de mudar de aparência são os agentes que atacam provocando essa "doença".

\section{“MaU-OlHado de BICHO"}

Para analisar o "mau-olhado de bicho", utilizo, além do conceito de perspectivismo, a categoria "perturbação físico-moral" utilizada por Duarte (1986) para designar aquelas doenças de caráter relacional que afetam simultaneamente os planos interpessoal e intrapessoal, resultando numa construção diferencial da pessoa. Não obstante Duarte (1998) restringir o sentido da categorização físicomoral ao interior de uma concepção dualista do ser humano, essa categoria possibilita, de acordo com o próprio autor, reconstituir a mediação de fenômenos como "transe" e "possessão" entre a corporalidade e outras dimensões, inclusive a espiritual.

A perturbação físico-moral denominada pelos ribeirinhos de "mauolhado de bicho"11 afeta tanto o indivíduo quanto o grupo, uma vez que existe a possibilidade de o "bicho atacar" outros membros da família ou da comunidade. Também afeta coletivamente porque mobiliza 0 grupo durante o itinerário terapêutico que muitas vezes ultrapassa os limites da comunidade onde a pessoa "atacada de bicho" reside, pois, dependendo da gravidade dos "sintomas", ela precisa recorrer aos cuidados de especialistas de cura (pajés, curadores, rezadores) residentes em outras comunidades e, inclusive, nas cidades da região.

0 "mau-olhado de bicho" é, frequentemente, consequência de um comportamento considerado condenável em relação ao uso dos recursos naturais, inobservância dos "regulamentos" estabelecidos pelos "donos", desrespeito às "paragens" pertencentes aos "bichos" ou da quebra da reciprocidade dos humanos entre si ou com os não-humanos. Nesse sentido, o "mau-olhado de bicho", ao

\footnotetext{
${ }^{11} \mathrm{Na}$ Amazônia, é notório o significado do olho e do olhar no estabelecimento, manutenção e rompimento das relações sociais.
} 
contrário do "mau-olhado de gente", resulta da intencionalidade de um demiurgo que se "engera".

Pessoa atacada pela "olhada de bicho" fica "maluca", "vira o zezeu" (endoidece), disseram meus informantes. Ela "grita dia e noite", sente dor de cabeça e febre porque o "mau-olhado de bicho desarruma a pessoa com sua malinação", e se não for tratada a tempo, vai perdendo a consciência de "gente", vai virando "bicho" e morre. Como resultado da "olhada" de um ser encantado, transforma-se em outro ser: "a pessoa fica que nem um bicho mesmo; da mesma qualidade do bicho. Fica fazendo o que o bicho faz, se não tratar". Isto é, vai perdendo a capacidade perceptiva e o comportamento tipicamente humanos.

Ser afetado pelo "olhar" de um "bicho" é interpretado como indicativo da possibilidade de a pessoa poder tornar-se pajé. Ao ser "atacada pela doença", aquela que se tornará pajé adquire o ponto de vista do ser que a "olhou" e, especialmente o "sacaca", será capaz de adquirir a aparência física de um "bicho" para visitar os "encantes". 0 pajé pode conversar com os "donos" quando está "invocado pelo bicho" durante os "trabalhos". Nesta circunstância informam aos homens sobre os "regulamentos" e realizam diagnósticos de outras pessoas acometidas de "assombro de bicho" ou outras doenças. Os ribeirinhos dizem que os "donos aparecem" através dele e transmitem um conjunto de conhecimentos sobre o comportamento a ser adotado em relação aos outros e seus espaços. Ou, nas palavras de um morador, por intermédio dos pajés os "bichos ensinam [as pessoas] a conviver com a natureza".

Também instrumentos de uso cotidiano, tal como os humanos, podem ser afetados e perder seu agenciamento, especialmente os apetrechos que "leva pro mato" (terçado, calçado, roupa, bolsa de cartucho, jamaxim) $)^{12}$ ou para pesca (canoa, rede, arpão, anzóis). Como eles também ficam "empanemados", precisam ser defumados juntamente com o seu proprietário para que sejam "curados", pois "se não fizer isso, não mata mais, não".

\section{Conclusão}

Minha etnografia indica que os ribeirinhos do baixo rio Tapajós exercem suas atividades cotidianas guiando-se por uma cosmologia segundo a qual não

\footnotetext{
${ }^{12}$ Maués e Motta Maués (1978) também fazem referência ao uso de defumação para curar espingarda empanemada.
} 
existe dicotomia ou antagonismo entre as dimensões naturais e sobrenaturais e na qual é possível a intervenção de seres sobrenaturais sobre a ordem natural e social. Sua cosmologia também admite o reconhecimento dos elementos do meio como possuindo poder de encantamento e a possibilidade de alguns seres se transformarem em outros. A relação com estes seres é possível porque os concebem como dotados de atributos humanos, tanto que a relação é tratada como sendo entre pessoas, "entidades morais" - em algumas situações, classificadas como parentes - e com as quais são estabelecidas relações sociais.

Com base no material etnográfico analisado, é possível concluir que o "mau olhado de bicho" implica na possibilidade de ruptura da identidade tipicamente humana, pois a pessoa, ao ser "atacada" pelos seres demiúrgicos que habitam a floresta e o rio, se não for convenientemente tratada, passa a ter o ponto de vista desses seres. Se o ponto de vista está no corpo, a perturbação físico-moral provocada pelo "olho de bicho" afeta-o, podendo resultar em perturbação de uma determinada coerência do mundo, pois, como sugere Le Breton (1995, p. 65), "pensar o corpo é outra maneira de pensar o mundo".

A categoria "engerar" denota a concepção de corpo como processo no qual ocorre uma permanente troca de aparência e de construção e desconstrução da pessoa, que é levada a adotar outros pontos de vista sobre si mesma e sobre os outros seres, humanos ou não-humanos, senão for convenientemente "curada". Essa concepção também revela que no pensamento dos ribeirinhos do Tapajós não haja uma dicotomia firmemente estabelecida do que seja gente e que existe uma porosidade na fronteira entre o mundo natural e 0 mundo não-natural, entre 0 humano e o não humano.

0 uso recorrente da categoria sugere ser bastante disseminada a ideia sobre a possibilidade de transformação dos seres uns nos outros e reforça a sugestão de Rivière (1995) segundo a qual na Amazônia o mundo é percebido como altamente transformacional e que as aparências são enganadoras. Ao tomar o corpo como objeto e suporte de diferenciação, reforça a ideia de serem enganadoras as aparências, pois podem ocultar diferenças na diferença, tendo, assim, implicações na vida social. A categoria salienta a apreensão do corpo como processo, experiência e expressão, bem como suas transformações implicam em mudanças identitárias, sobretudo se for admitido que o "mau-olhado de bicho" interfere na construção diferencial da pessoa. Se minha análise for adequada, ela 
evidencia uma das principais características do perspectivismo: a permutabilidade dos seres mediante a transformação virtual dos corpos.

0 material etnográfico indica ser adequado pensar o corpo de alguém com "mau-olhado de bicho" e submetido ao itinerário terapêutico como um corpo performado que implica também em alterações de suas capacidades perceptivas. Suspeito que tal forma de "doença" implique na possibilidade de ruptura de uma identidade tipicamente humana, pois ao ser "invocada" pelos seres encantados a pessoa passaria também a ter o ponto de vista deles, especialmente os pajés, ou seja, se o ponto de vista está no corpo, o "mau-olhado de bicho" afeta-o especialmente. Assim, as perturbações provocadas pelo "olho do bicho" podem resultar numa modificação de uma determinada coerência do mundo.

Ainda que a transformação dos corpos dos seres não se verifique materialmente, a afetação da percepção do corpo e das suas capacidades perceptivas causadas pelas perturbações provocadas pelo "olho do bicho" alteram a identidade da pessoa e indicam que tais dimensões se cruzam, ao menos no nível do pensamento. Entretanto, compreender as concepções e práticas relativas ao corpo, à saúde/doença e à pessoa num contexto em que o sistema cosmológico postula a permutabilidade dos seres e interage com outras formas de objetivação da natureza exige a realização de estudos etnográficos mais amplos.

Finalmente, compreender o pensamento que postula sobre a capacidade de transformação ou hibridação dos seres e as práticas a ela associada possibilitará colocar em perspectiva problemas postos pela intervenção cada vez mais intensa da biotecnologia sobre os corpos humanos. Intervenções que implicam num embaralhamento ou redução das fronteiras entre o humano e o não-humano.

\section{REFERÊNCIAS}

ALENCAR, Edna Ferreira. Terra caída: encante, lugares e identidades. 2002. Tese (Doutorado em Antropologia) - Universidade de Brasília, Brasília.

ARHEM, Kaj. Ecosofia Makuna. In: CORREA, François. La selva humanizada: ecologia alternativa en el tropico húmedo colombiano. Bogotá: Instituto Colombiano de Antropologia, 1993. p. 109-126. 
The cosmic food web: human-nature relateness in the Northwest Amazon. In: DESCOLA, P Philippe; PALSSON, Gisli (Ed.). Nature and society: antropological perspectives. Londres: Routledge, 1996. p. 185-204

CRAVALHO, Mark. An invisible universe of evil: supernatural malevolence and personal experience among Amazon peasant. 1993. Dissertação (Doutorado em Antropologia) - University of Califórnia, San Diego.

KNAUTH, Daniela. De doente a "encantado": o conceito de mecanismo de defesa constituído culturalmente e a experiência de uma vítima de "espírito mau" em uma comunidade rural na Amazônia. In: ALVES, Paulo César;RABELO, Miriam Cristina. Antropologia da saúde: traçando identidade e explorando fronteiras. Rio de Janeiro: Relume Dumará, 1998. p. 157-177.

DA MATTA, Roberto. Conta de mentiroso: sete ensaios de antropologia brasileira. Rio de Janeiro: Rocco, 1993.

. Panema: uma tentativa de análise estrutural. In: . Ensaios de antropologia estrutural. Petrópolis: Vozes, 1973.

DESCOLA, Philippe. Ecologia e cosmologia. In: CASTRO, Edna; PINTON, Florence (Org.). Faces do trópico úmido: conceitos e novas questões sobre desenvolvimento e meio ambiente. Belém: CEJUP, 1997. p. 234-261.

. Societies of nature and the Nature of society. In: KUPER, Adam (Ed.). Conceptualizing society. Londres: Routledge, 1992. p. 107-125

DUARTE, Luiz. Da vida nervosa nas classes trabalhadoras. Rio de Janeiro: Jorge Zahar, 1986.

Fernando Dias: pessoa e dor no ocidente. Horizontes Antropológicos, Porto Alegre, v. 4, n. 9, p. 13-28, 1998.

DUMONT. Louis. O individualismo: uma perspectiva antropológica da ideologia moderna. Rio de Janeiro: Rocco, 1993.

ERIKSON, Philippe. "I", "UUU”, "SHHH”: gritos, sexo e metamorfose entre os Matis (Amazônia Brasileira)”. Rio de Janeiro, Mana, v. 6, n. 2, p. 37-64, 2000.

FAUSTO, Carlos. Donos de mais: maestria e domínio na Amazônia. Mana, Rio de Janeiro, v. 14, n. 2, p. 329-366, 2008.

GALVÃO, Eduardo. Santos e visagens. São Paulo: Nacional, 1976. 
HARRIS, Mark. Life on the Amazon: the anthropology of a brazilian peasant village. Oxford: Oxford University Press, 2000.

INGOLD, Tim. Humanidade e animalidade. Revista Brasileira de Ciências Sociais, São Paulo, v. 10, n. 28, p. 39-53, 1995.

KOK, Glória. Os vivos e os mortos na América Portuguesa: da antropofagia à água do batismo. Campinas: UNICAMP, 2001.

LATOUR, Bruno. A esperança de Pandora. Bauru: EDUSC, 2001.

LE BRETON, David. A sindrome de Frankenstein. In: SANT ANNA, Denise. B. (Org.). Políticas do corpo. São Paulo: Estação Liberdade, 1995. p.49-67.

LOUREIRO, João de Jesus Paes. Cultura Amazônica: uma poética do imaginário. Belém: CEJUP, 1995.

LUNA, Luis Eduardo. Xamanismo amazônico, ayahuasca, antropomorfismo e mundo natural. In: LABATE, Beatriz C.; ARAÚJO, Wladimir S. (Org.). O uso ritual da ayahuasca. São Paulo: Mercado de Letras, 2002. p. 181-200.

MAUÉS, Raymundo Heraldo. A ilha encantada: medicina e xamanismo numa comunidade de pescadores. Belém: NAEA, 1997.

MAUÉS, Raymundo Heraldo; MOTTA-MAUÉS, Maria Angélica. 0 modelo da reima: representações alimentares em uma comunidade amazônica. Anuário Antropológico, Rio de Janeiro, n. 77, p. 120-147, 1978,

NUNGENT, Stephen. Amazonian caboclo society: an essay on invisibility and peasant economy. Oxford: Berg, 1993.

RIVAL, Laura. Domestication as a historical and symbolic process wild gardens and cultivated forests in the ecuadorian Amazon. In: BALÉE, William (Org.).Advances in bistorical ecology. New York: Columbia University Press, 1998. p. 232-250.

RIVIÈRE, Peter. AAE na Amazônia. Revista de Antropologia, São Paulo, v. 38, n. 1, p. 191-203, 1995.

SILVA, Tatiana Lins e. Os curupira foram embora: economia, política e ideologia numa comunidade amazônica. 1980. Dissertação (Mestrado) - Universidade Federal do Rio de Janeiro, Rio de Janeiro.

SLATER, Candace. A festa do Boto: transformação e desencanto na imaginação. Rio de Janeiro: FUNARTE, 2001. 
SMITH, Nigel. The enchanted amazon rainforest: stories from a vanishing world. Gainsville: University Press of Florida, 1996.

TEIXEIRA, Carlos C. O aviamento e o barracão na sociedade do seringal. 1980. Dissertação (Mestrado). Universidade de São Paulo, São Paulo.

VIVEIROS DE CASTRO, Eduardo. A inconstância da alma selvagem e outros ensaios de antropologia. São Paulo: Cosac\&Naif, 2002.

Os pronomes cosmológicos e o perspectivismo ameríndio. Mana, Rio de Janeiro, v. 2, n. 2, p. 115-144, 1996.

WAGLEY, Charles. Uma comunidade amazônica. Belo Horizonte: Itatiaia/ Edusp, 1988.

WAWZYNIAK, João Valentin. Assombro de olhada de bicho: uma etnografia das concepções e ações em saúde entre ribeirinhos do baixo rio Tapajós, Pará - Brasil. 2008. Tese (Doutorado em Ciências Sociais) - Universidade Federal de São Carlos, São Carlos.

. Curupira "engerado" em Ibama: apreensão de um órgão público federal em termos cosmológicos. Teoria e Pesquisa, São Carlos, n. 44/45, p. 5-18, 2004. 